\title{
Diagnosis and excision of a primary hydatid cyst localized in the soft tissue
}

\author{
Guray Demir ${ }^{[1]}$, Ali Tekin ${ }^{[2]}$ and Hande Tekin ${ }^{[3]}$
}

[1]. Department of Anesthesiology and Reanimation, Bakirkoy Dr. Sadi Konuk Training and Research Hospital, Istanbul, Turkey. [2]. Department of Pediatric Surgery, Tatvan State Hospital, Bitlis, Turkey. [3]. Department of Pediatrics, Tatvan State Hospital, Bitlis, Turkey.

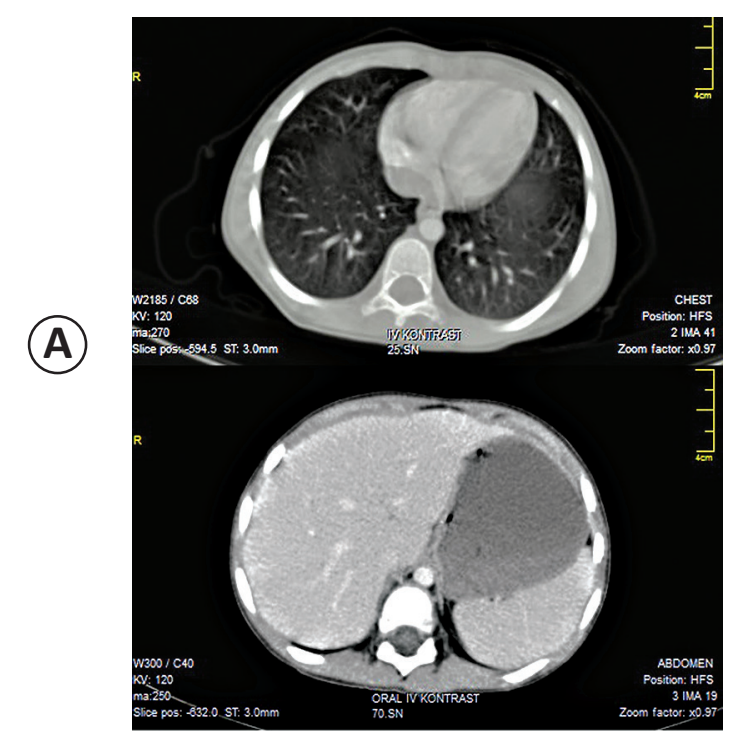

A 7-year-old boy presented with a painful swelling on his chest wall under the left clavicula. His parents reported that this mass had developed and increased in size within the previous year. Physical examination showed a fluctuant mass $(3 \times 4 \mathrm{~cm})$ within the indicated region; this mass elicited pain on palpation. Ultrasonographic examination did not reveal any diagnostic clues. Considering that the patient's family lived in a region endemic for hydatid disease and were involved in livestock farming, the patient underwent further assessments using abdominal and thoracic computed tomography (CT) examinations, specific immunoglobulin E (IgE) tests, and hemagglutination tests to confirm a diagnosis of hydatid cyst. The serologic test results were normal. CT did not show any cystic lesions in the liver, lungs, or other intraabdominal organs (Figure A). However, a mass, measuring $28 \times 38 \mathrm{~mm}$, similar to a unilocular cyst, was observed on the anterior thoracic wall just below the left clavicle (Figure B). For definitive diagnosis,

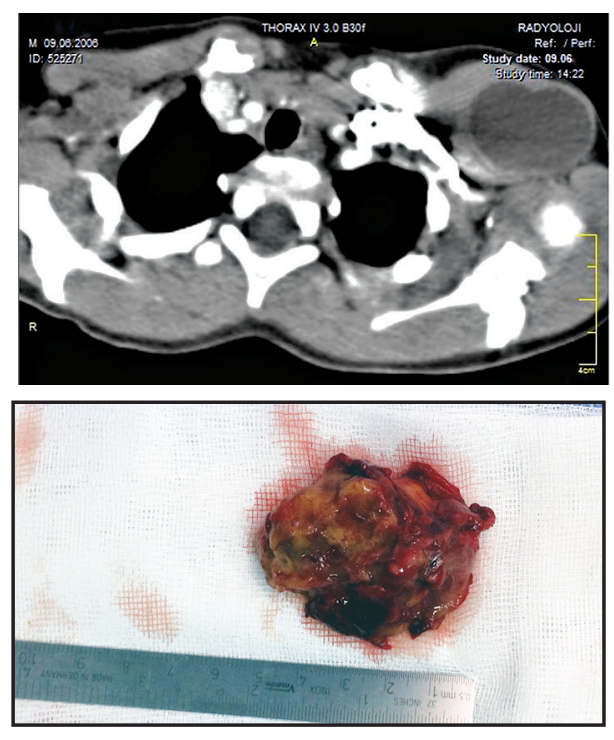

(B)

(C)

and treatment of the mass, excisional biopsy was scheduled. The mass was excised in compliance with the principles of the surgical procedure; however, the cyst wall ruptured revealing a germinative membrane. The mass was extirpated, and prepared for histopathological examination (Figure C). On the basis of the findings of the histopathological examination, a diagnosis of hydatid cyst was confirmed.

\section{REFERENCES}

1. Vercelli-Retta J, Mañana G, Reissenweber NJ. The cytologic diagnosis of hydatid disease. Acta Cytol 1982; 26:159-168.

2. Ousadden A, Elbouhaddouti H, Ibnmajdoub KH, Mazaz K, Aittaleb K. A solitary primary subcutaneous hydatid cyst in the abdominal wall of a 70-year-old woman: a case report. J Med Case Rep 2011; 5:270.

3. Eckert J, Deplazes P. Biological, epidemiological, and clinical aspects of echinococcosis, a zoonosis of increasing concern. Clin Microbiol Rev 2004; 17:107-135.

Address to: Dr. Guray Demir. Department of Anesthesiology and Reanimation/Bakirkoy Dr. Sadi Konuk Training and Research Hospital. Zuhuratbaba Mh, 34147 Istanbul, Turkey.

Phone: 009021 2414-7171; Fax: 009021 2542-4491

e-mail: guraydemir@hotmail.com

Received 14 March 2014

Accepted 22 May 2014 